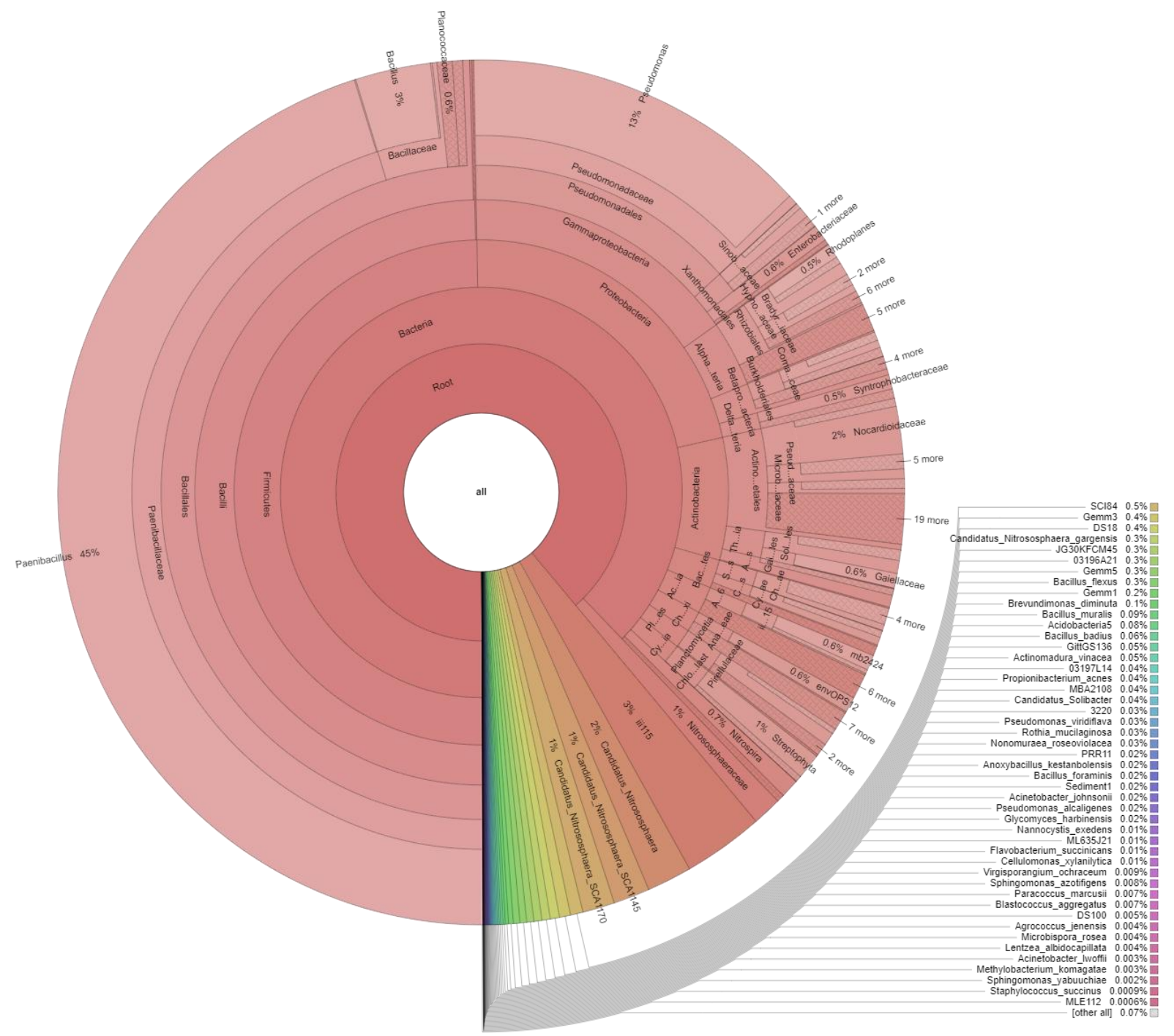

M15

Supplementary fig. 1 


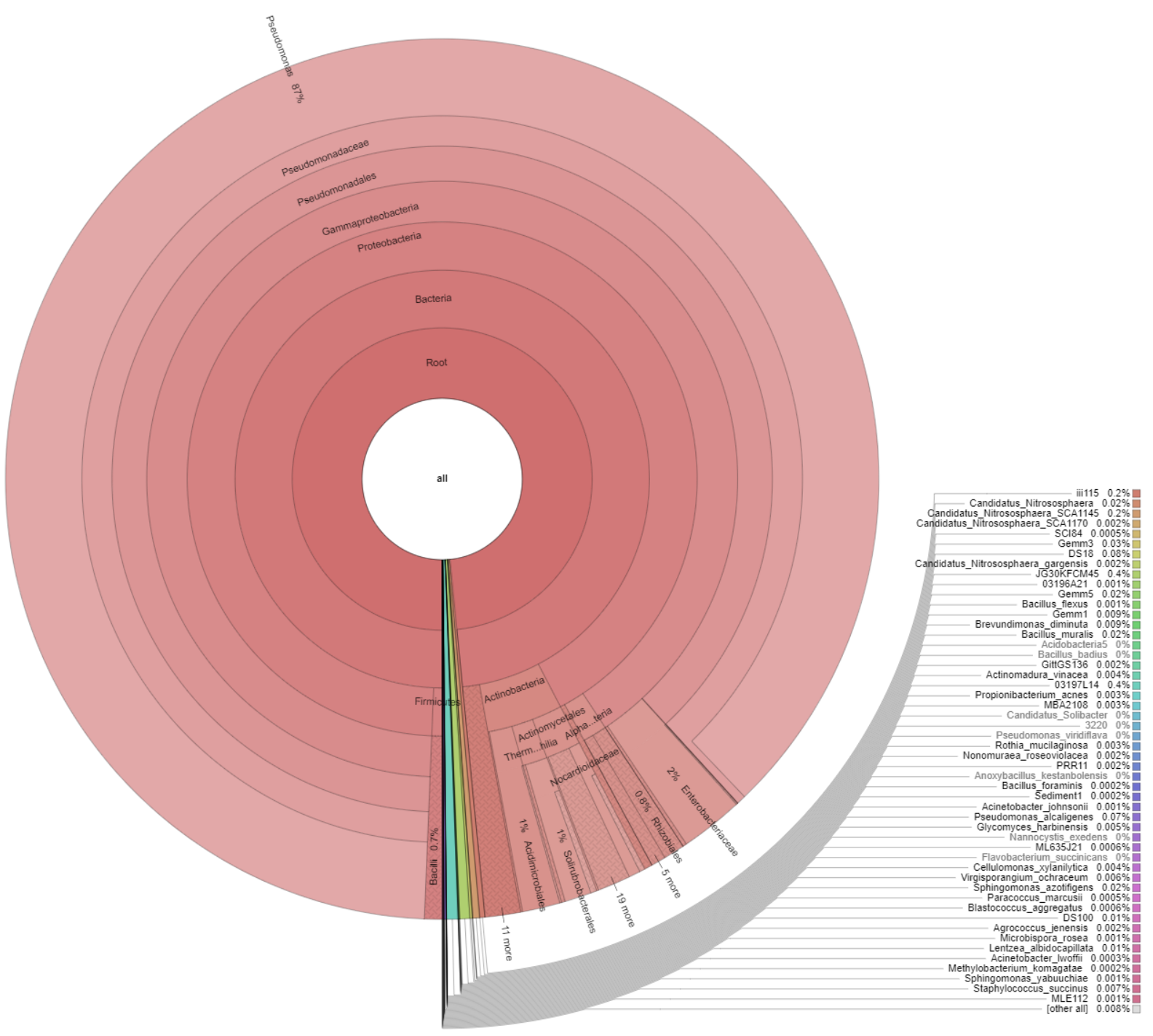

M5

Supplementary fig. 2 


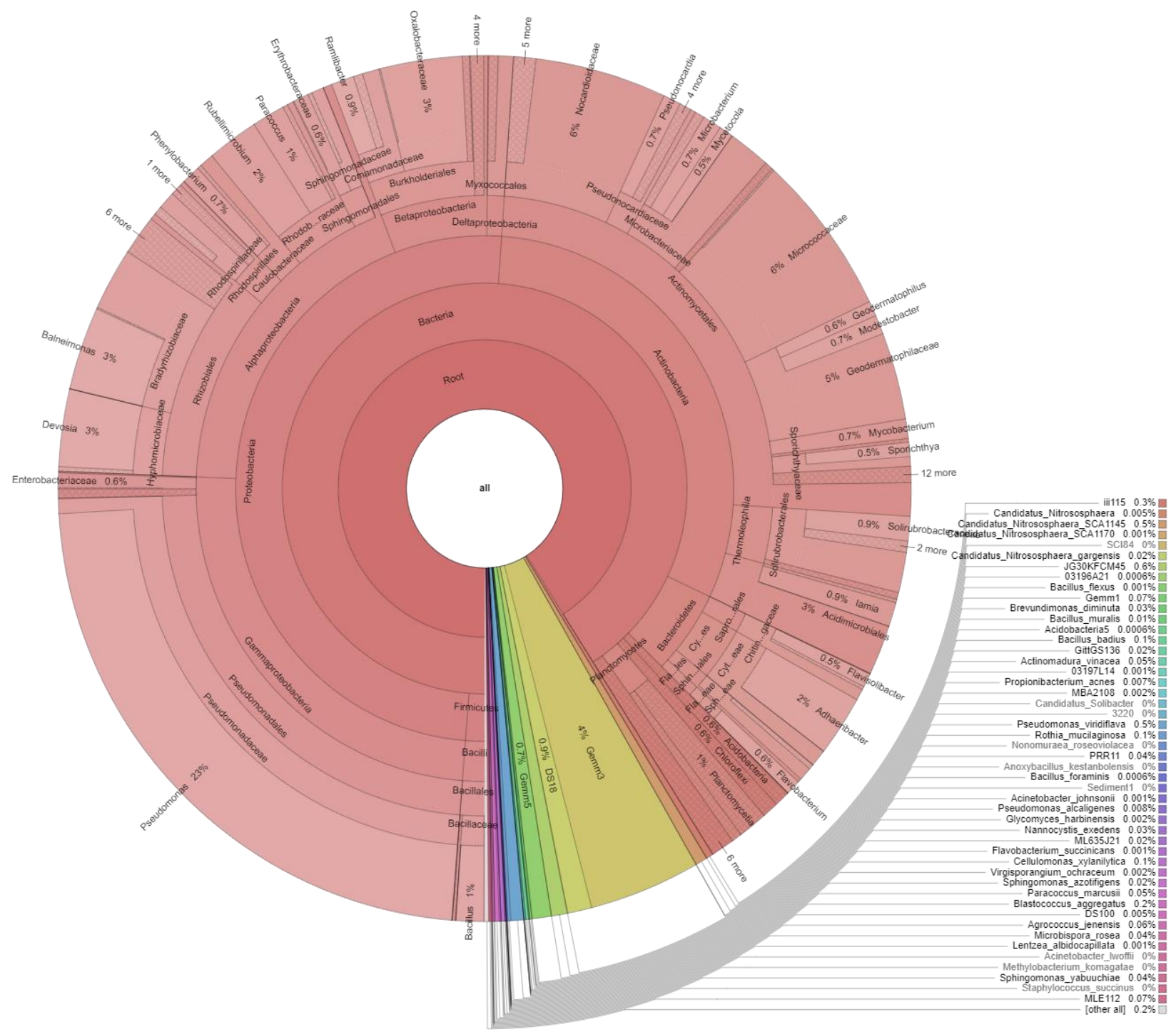

ABHA

Supplementary fig. 3 


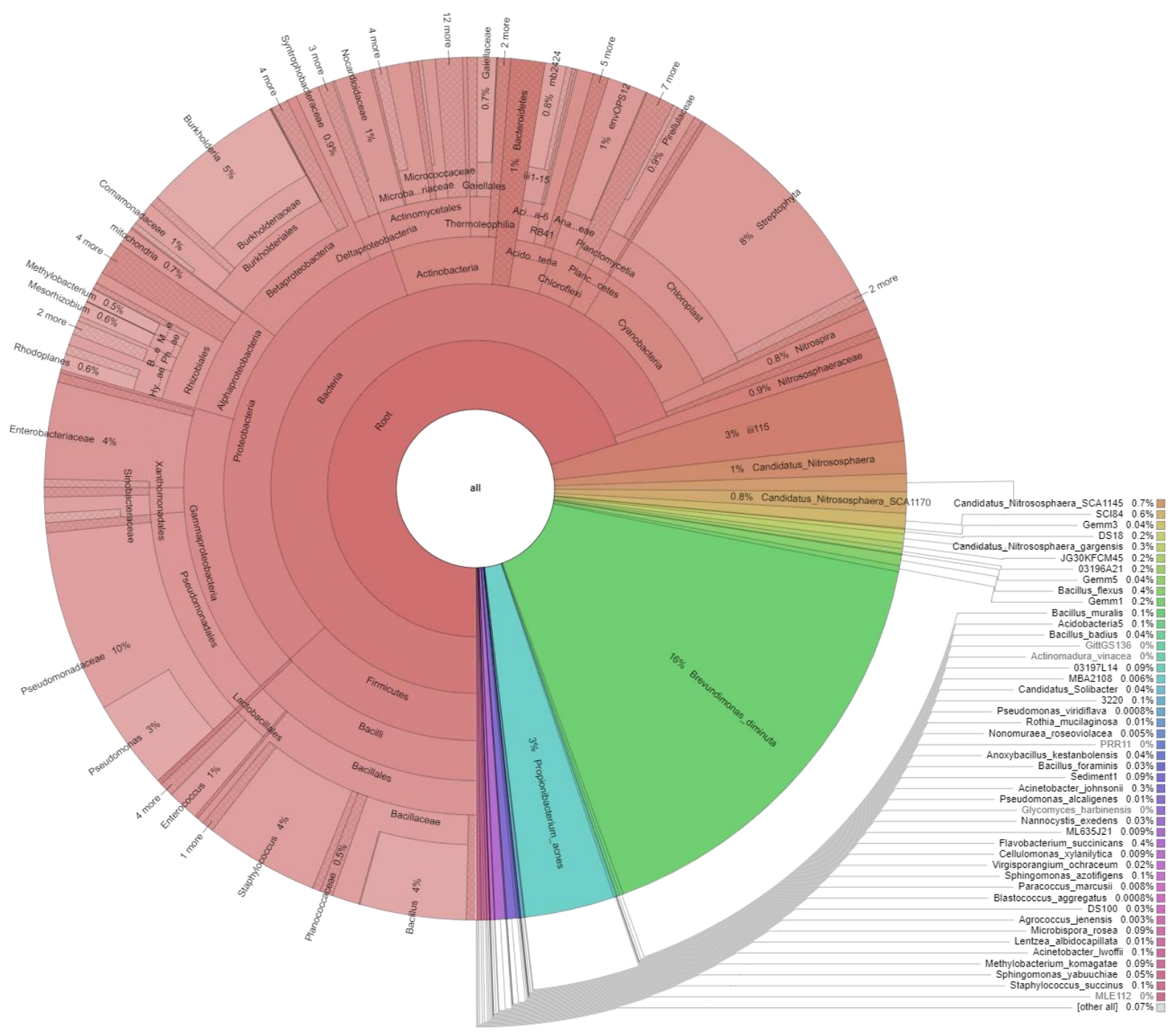

\section{Hafr Al-Batin}

Supplementary fig. 4 